\title{
A Study of Lateral Nasal Wall: Anatomical Variants,Radiological And Endoscopic Appearance And Role in Symptomatology in Chronic Rhinosinusitis
}

\author{
Navreet Jaura ${ }^{1}$,Sanjeev Bhagat ${ }^{2}$, Manwinder Singh ${ }^{3}$,Baldev Singh ${ }^{4}$, \\ Manoj Mathur, Girish Dogra

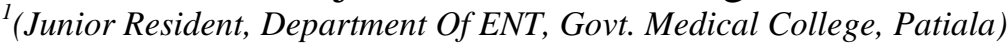 \\ ${ }^{2}$ (Associate Professor, Department Of ENT, Govt. Medical College, Patiala) \\ ${ }^{3}$ (Senior Resident, Department Of ENT, Govt. Medical College, Patiala) \\ ${ }^{4}$ (Professor,Department Of ENT, Govt. Medical College, Patiala) \\ ${ }^{5}$ (Associate Professor, Deptt. Of Radiodiagnosis, Govt. Medical College, Patiala) \\ ${ }^{6}$ (Senior Resident, Department Of ENT, Govt. Medical College, Patiala)
}

\begin{abstract}
It is assumed that the anatomical variations of lateral wall of nose contribute to various disease symptoms by blocking normal sinus drainage.This prospective study was conducted on hundred patients suffering from chronic rhinosinusitis, to study the various anatomical variations of lateral wall of nose by CT scan and diagnostic nasal endoscopy.A statistically significant correlation was found between concha bullosa and maxillary sinusitis (right and left concha bullosa with ipsilateral maxillary sinusitis $p$ value was 0.033 and 0.01 , respectively which are <0.05), right and left agger nasi cell and ipsilateral frontal sinusitis ( $p$ value is. 01 and. 0006 which are <.05), right and left paradoxical middle turbinate and ipsilateral maxillary sinusitis ( $p$ value is. 000 and. 000 which are <.05).Considering the results obtained, we conclude that anatomical variations of the nose and paranasal sinusescan play an important role in the pathogenesis of chronic rhinosinusitis, and thus may increase the risk of sinus mucosal disease.
\end{abstract}

Keywords: Chronic rhinosinusitis, Diagnostic nasal endoscopy, Concha bullosa, Agger nasi cells, Paradoxical middle turbinate.

\section{Introduction}

Chronic rhinosinusitis(CRS) is a condition that is increasing in proportions throughout the world. It has been known to negatively impact health related quality of life ${ }^{[1]}$ It's a common disease affecting over 30 million individuals globally each year with more than 200,000 people annually requiring surgical intervention. There are numerous narrow clefts in lateral wall of nose, many anatomical variations that can easily narrow these clefts and thus predispose to recurring infection. ${ }^{[2]}$ Several authors have assessed the relationship between sinonasal anatomic variants and the incidence of rhinosinusitisCT scan of nose and paranasal sinuses plays a central role in the modern management of chronic rhinosinusitis due to its ability to delineate mucosal disease, to demonstrate a primary obstructive pathology and to image distal structures such as the posterior ethmoid sinus that cannot be viewed with direct endoscopy. CT scan with its excellent capability of displaying bone and soft tissue is the current diagnostic modality of choice for sinonasal disease. The coronal plane is considered to be the best orientation for evaluation of the sinonasal tract as it clearly shows the ostiomeatal complex and the relationship of the brain to the ethmoidal roof and correlates closely with the surgical orientation.Nasal endoscopy combined with $\mathrm{CT}$ has made the approach to sinonasal disease more specific, rational and accurate.Anatomic variations, such as deviation of the nasal septum, concha bullosa or paradoxical middle turbinate, ethmoidal bulla hypertrophic, agger nasi cell, lateral or medial bending of uncinate process (UP) and haller cell are common and emphasized in routine evaluation of computed tomography (CT) images. ${ }^{[5]}$ However, their roles in pathogenesis of rhinosinusitis are still unclear. Theoretically, these variants could shift and compress osteomeatal complex components, determining an obstruction to the paranasal sinuses mucus drainage and further predispose to sinusitis. However, this concept is still controversial and the presence of any anatomical variation does not necessarily establish aetiology for rhinosinusitis. There is not much literature available regarding the anatomical variations of paranasal sinuses in the population residing in northern India. It is important for us to describe these variations among our population and establish the associations if present, between the variations and the genesis of CRS.The present study was aimed at studying the most frequently encountered anatomical variations in lateral wall of nose that may predispose to various symptoms in chronic rhinosinusitis patients. 


\section{Material And Methods}

This study was conducted on 100 adult patients attending the outdoor of the Department of ENT, Government Medical College and Rajindra Hospital, Patiala.A clinical diagnosis of chronic rhinosinusitis was made on clinical criteria reported by the Task Force on rhinosinusitis. All patients of age $>18$ years underwent examination by diagnostic nasal endoscopy. The study excluded patients with alteration in paranasal anatomy due to facial trauma, tumours of sino-nasal mucosa, previous sinus surgery, acute infection, nasal polyps, nasal mass, bleeding disordersPatient work up was done taking a detailed history about symptoms and their duration. Patients included in the study were subjected to CT Scan- Nose and Paranasal Sinuses- Coronal View and axial view, with contiguous $3 \mathrm{~mm}$ thick images in coronal plane. Diagnostic Nasal Endoscopy (DNE) was done in all cases to confirm or discard the CT findings, after anaesthetizing and decongesting the nasal mucosa instilling $4 \%$ xylocaine along with a vasoconstrictor. 0 degree and 30 degree $4 \mathrm{~mm}$ endoscope was used. The anatomical variations findings were noted down. All the information was entered in a predesigned proforma and analyzed statistically applying chi square testand $\mathrm{p}$ value $<0.05$ was significant and $\mathrm{p}<0.001$ was highly significant.

\section{Results}

This study was conducted on 100 adult patients. Age distribution of patients varied from 15 years to 75 years. The majority of the patients $(34 \%)$ were in the age group of 26 to 35 years. The sex distribution showed a male preponderance with $66 \%$ males and $34 \%$ females. Headache was the most common symptom occurring in $84 \%$, followed by Nasal discharge in $81 \%$, Post nasal drip in $76 \%$, nasal obstruction in $70 \%$. Maximum number of patients, i.e, $86 \%$ had symptoms for 1-5 years, 5\% patients had symptoms for less than 1 year and $9 \%$ patients had symptoms for more than 5 years. The most common anatomical variation seen was Agger nasi cells (Fig-3), which were present in $78 \%$ patients. [unilateral in $26 \%$ and bilateral in $52 \%$ ]. Deviated nasal septum was present in $76 \%$ patients. Inferior turbinate hypertrophy was seen in $74 \%$ patients (unilateral in $34 \%$ and bilateral in 40\%).Concha bullosa (Fig -1) was seen in 66\% patients (unilateral in 36\% and bilateral in 30\%).. Pneumatized middle turbinate( concha bullosa) was seen in $66 \%$ patients with unilateral in $36 \%$ patients and bilateral in 30\% patients. Hence 96 turbinates were studied. Lamellar pattern was seen in $44.79 \%$ sides, bulbous pattern in $10.42 \%$ sides. True concha bullosa pattern was seen in $38.54 \%$. Uncinate process variation present in $64 \%$ patients (unilateral in $34 \%$ and bilateral in 30\%).Bulla ethmoidalis was present in $29 \%$ patients. Paradoxical middle turbinate(Fig.2) was present in $22 \%$ patients. Haller's cells were found in $4 \%$ patients. All were unilateral. Accessory maxillary ostia were seen in $20 \%$ patients and $16 \%$ were unilateral and $4 \%$ were bilateral. The uncinate was found to be typical in 64\%. [Type I - in 48\%, Type II in $10 \%$ and Type III in 6\%]. The maximum number of attachments were seen to lamina papyracea.

CT scan nose and paranasal sinuses were done to see the extent of mucosal hypertrophy. Mucosal hypertrophy was seen most commonly in osteomeatal complex in $82 \%$ patients which was unilateral in $46 \%$ patients and bilateral in $36 \%$ patients. Maxillary sinus mucosal hypertrophy was seen in $87 \%$ patients which being unilateral in $45 \%$ and bilateral in $42 \%$ patients. Mucosal hypertrophy of anterior ethmoids was seen in $77 \%$ patients which was unilateral in $38 \%$ patients and bilateral in $39 \%$ patients. Posterior ethmoids were involved in $56 \%$ patients which being unilateral in $30 \%$ patients and bilateral in $26 \%$ patients. Mucosal hypertrophy of frontal sinus was seen in $64 \%$ patients which was unilateral in $40 \%$ patients and bilateral in $24 \%$ patients. Sphenoid sinus was involved in $20 \%$ patients which was unilateral in $9 \%$ patients and bilateral in $11 \%$ patients(Table-1).We found a statistically significant correlation between concha bullosa and maxillary sinusitis (right and left concha bullosa with ipsilateral maxillary sinusitis p value is 0.033 and 0.01 , respectively which are < 0.05), right and left agger nasi cell and ipsilateral frontal sinusitis (p value is. 01 and. 0006 which are $<.05$ ) and in total $\mathrm{p}$ value is. 029 which is again <.05, right and left paradoxical middle turbinate and ipsilateral maxillary sinusitis ( $\mathrm{p}$ value is. 000 and. 000 which are <.05) and in total $\mathrm{p}$ value is. 000 which is again $<.05$. (Table 2).

Table-1 Table Showing Incidence Of Anatomical Variations On Ct Scan

\begin{tabular}{|c|c|c|c|}
\hline \multirow{2}{*}{$\begin{array}{c}\text { Anatomical } \\
\text { Variation }\end{array}$} & $\begin{array}{c}\text { No. of Patients } \\
(\mathbf{n = 1 0 0})\end{array}$ & $\begin{array}{c}\text { No. of Patients } \\
(\mathbf{n = 1 0 0})\end{array}$ & $\begin{array}{c}\text { No. of Patients } \\
(\mathbf{n = 1 0 0})\end{array}$ \\
\cline { 2 - 4 } & Unilateral & Bilateral & Total \\
\hline Agger Nasi Cell & $26 \%$ & $52 \%$ & $78 \%$ \\
\hline Deviated Nasal Septum & - & - & $76 \%$ \\
\hline Inferior Turbinate Hypertrophy & $34 \%$ & $40 \%$ & $66 \%$ \\
\hline Concha Bullosa & $36 \%$ & $30 \%$ & $64 \%$ \\
\hline Uncinate process variations & $34 \%$ & $30 \%$ & $29 \%$ \\
\hline Enlarged Bulla Ethmoidalis & $14 \%$ & $15 \%$ & $22 \%$ \\
\hline Paradoxical Middle Turbinate & $19 \%$ & $3 \%$ & $20 \%$ \\
\hline Accessory Maxillary Ostia & $16 \%$ & $4 \%$ & $5 \%$ \\
\hline Onodi cell & $5 \%$ & - & \\
\hline
\end{tabular}




\begin{tabular}{|c|c|c|c|}
\hline Haller's Cells & $4 \%$ & - & $4 \%$ \\
\hline & & & \\
\hline
\end{tabular}

Table-2 Statistically Significant Correlation Between Anatomical Variations And Sinusitis

\begin{tabular}{|c|c|c|}
\hline Anatomical variation & Sinusitis & p value \\
\hline Concha bullosa & Maxillary sinusitis & $.0004(<0.05)$ \\
Right & Right & $.033(<0.05)$ \\
Left & Left & $.01(<0.05)$ \\
\hline Agger nasi cells & Frontal sinusitis & $.029(<0.05)$ \\
Right & Right & $.01(<0.05)$ \\
Left & Left & $.0006(<0.05)$ \\
\hline Paradoxical middle turbinate & Maxillary sinusitis & $.000(<0.05)$ \\
Right & Right & $.000(<0.05)$ \\
Left & Left & $.000(<0.05)$ \\
\hline DNS & Maxillary sinusitis & $.04(<0.05)$ \\
Right & Right & $.015(<0.05)$ \\
Left & Left & $.006(<0.05)$ \\
\hline
\end{tabular}
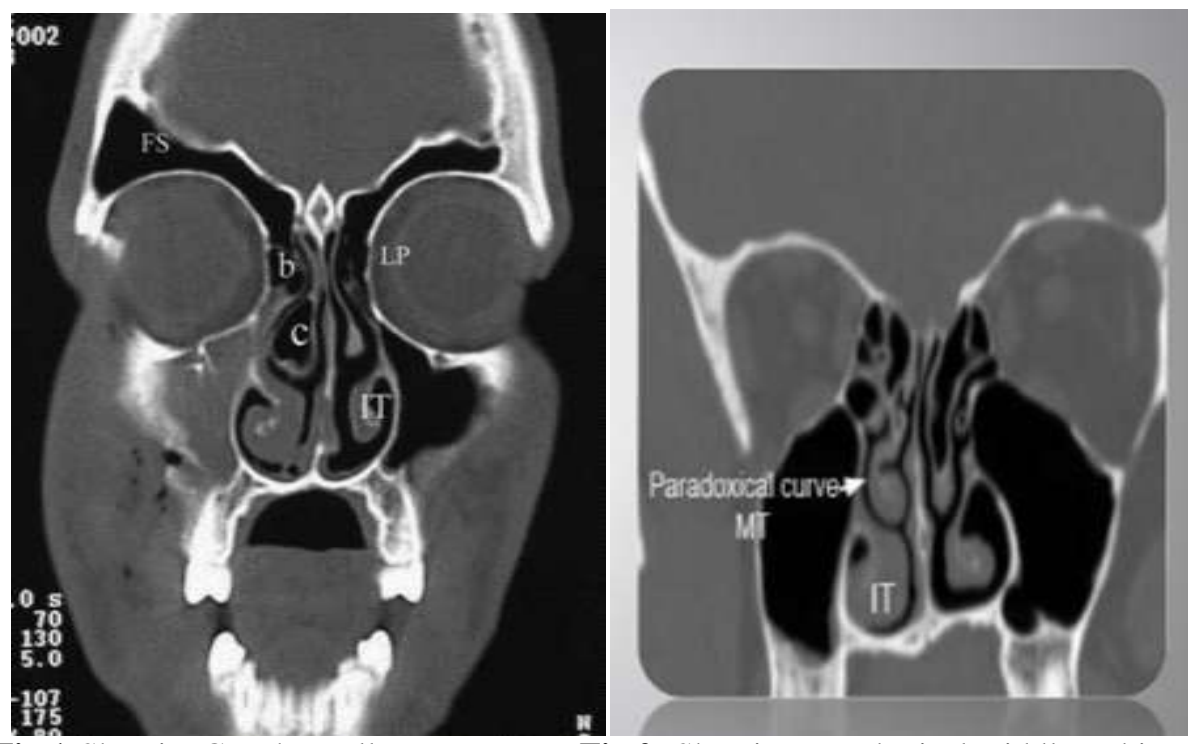

Fig.1:ShowingConcha Bullosa

Fig.2: Showing paradoxical middle turbinate

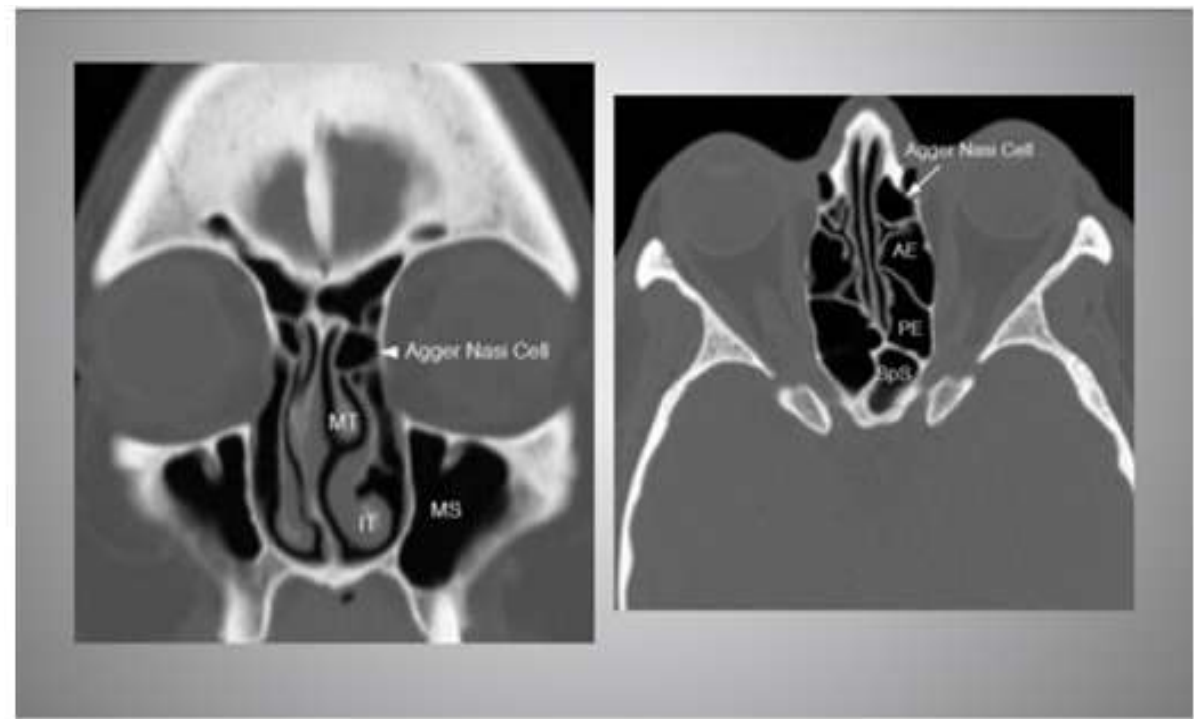

Fig.3: Showing Agger nasi cells

\section{Discussion}

The variations in lateral wall of nose perpetuates the sinus disease. This in turn requires the surgeons to have detailed knowledge of the anatomy of the lateral nasal wall, paranasal sinuses and surrounding vital structures and of the large number of anatomical variants in the region.Disruption of the mucociliary clearance due to anatomic variations and mucosal disease of the osteomeatal complex is considered to be the prime factor 
for the continuation of symptoms and chronicity of rhinosinusitis. Functional endoscopic sinus surgery (FESS) addresses these anatomical variations and mucosal diseases and restores the normal physiology of the paranasal sinuses. For FESS to be effective, accurate localization of the disease is very important. Although nasal endoscopy is very helpful, the convoluted anatomic framework of the ethmoids precludes the direct noninvasive endoscopic evaluation of deeper osteomeatal complex, posterior ethmoids and sphenoid sinus disease $^{[7]}$. CT scan has proved to be indispensable in identifying the magnitude and extent of the disease in sinonasal areas.

In our study we found that the headache was most common symptom which could be sinogenic origin or contact headache $(84 \%)$. This was followed by nasal discharge $(81 \%)$ which could be explained by the fact that variants can cause narrowing of middle meatus leading to inspissations of secretions and thereby causing discharge. The symptoms of post nasal drip and nasal obstruction were present in $76 \%$ and $70 \%$ patients respectively.

Wani et $\mathrm{al}^{[4]}$ et al in their study found headache and facial pain as the main symptom in $90 \%$ cases, nasal discharge in $86.6 \%$, nasal obstruction in $85.33 \%$ and hyposmia in $20 \%$ cases.In a study by Sheetal et al ${ }^{[8]}$, the most common symptom of presentation was headache in $90 \%$ followed by nasal discharge in $80 \%$. Madani et $\mathrm{al}^{[9]}$ in their study found the following symptoms, nasal obstruction $(24.3 \%)$, headache $(21.9 \%)$, nasal congestion $(18.5 \%)$ and post nasal discharge $(16.6 \%)$. Kolvekar et $\mathrm{al}^{[10]}$ in their study found, nasal obstruction $(42.66 \%)$, headache and facial pain $(34.66 \%)$,running nose $(29.33 \%)$, nasal bleeding $(4 \%)$. El-Shazly et al ${ }^{[11]}$ found refractory frontal headache in $92.8 \%$ of patients, thus our study correlates to Wani et al ${ }^{[4]}$, Sheetal et al ${ }^{[8]}$ and El-shazly et $\mathrm{al}^{[11]}$.

Agar nasi cell was the most common anatomical variation in our study. Agger nasi cells were found to be present in $78 \%$ patients. It was unilateral in $26 \%$ and bilateral in $52 \%$. The prevalence of agger nasi cells varies widely possibly due to the factors like different definition assigned to this anatomical variation and may be the small size of agger nasi cell makes its detection difficult in some studies. Our results are close to those reported by Leunig et $\mathrm{al}^{[12]}(80 \%)$.

Out of 200 sides, superior insertion of uncinate process could be identified definitely in 94 sides. We found Type I uncinate process in $70(74.4 \%)$ of 94 sides, Type II uncinate process seen in $14(14.8 \%)$ of 94 sides, Type III uncinate process seen in $10(10.6 \%)$ of 94 sides.Landsberg et al ${ }^{[13]}$ studied 144 CT scans for superior attachment of uncinate Process out of possible 288 sides, they were able to identify superior attachment in 173 sides $(60 \%)$ and most common type of uncinate attachment was to lamina papyracea in $52 \%$ sides. Turgut et al ${ }^{[14]}$ studied CT scan of 243 patients (486 sides), they were able to identify superior attachment in 361 (74\%) of 486 sides. They found insertion of uncinate process to lamina papyracea was the most common type found in $226(63 \%)$ of the 361 sides followed by insertion into skull base in $52(14 \%)$ of the 361 sides. Our study is similar to those by Turgut et $\mathrm{al}^{[14]}$ in showing that the most common superior attachment of uncinate process was to lamina papyracea.

We found pneumatized middle turbinate (concha bullosa) in $66(66 \%)$ patients. Out of these, unilateral concha bullosa was seen in $36(36 \%)$ patients and bilateral in $30(30 \%)$ patients. Of the 96 turbinates studied, lamellar pattern was seen in $44.79 \%$ sides, bulbous pattern in $10.42 \%$ sides and true pattern was the most common seen in $38.54 \%$ sides. Concha bullosa may be a contributing factor in the pathogenesis of sinus inflammatory disease by blocking the entrance of middle meatus. The reported prevalence of choncha bullosa could vary according to differing opinions regarding significant degrees of pneumatisation. Our results correlate well with those, reported by Cagiciet $\mathrm{al}^{[15]}$ and Azila et $\mathrm{al}^{[6]}$,i.e.,69\% and $62.5 \%$ respectively. Less prevelance of concha bullosa in Wani et $\mathrm{al}^{[4]}(30 \%)$ can be explained by the factors like diverse study population, different criteria for pneumatisation and analytical methods.

Paradoxical middle turbinate was seen in $22 \%$ patients, being unilateral in $19 \%$ patients and bilateral in $3 \%$ patients. Normally, the convexity of the middle turbinate bone is directed medially, toward the nasal septum. When paradoxically curved, the convexity is directed laterally, toward the lateral sinus wall. Although no studies relate this variation to sinus disease, it is a presumed etiologic factor because of the deformity and obstruction or alteration of nasal passage air flow dynamics, especially when associated with other variations.

In our study, Haller's cells were seen in $4 \%$ patients. All of them were unilateral. Literature shows a wide range of variation in their occurrence. The prevalence of haller cells in current study is comparable to study done by Gupta et $\mathrm{al}^{[16]}$ and Stoney et al ${ }^{[17]}$,i.e.3.2\% and $7 \%$ respectively. Also called the infraorbital ethmoidal cells, these are anterior ethmoidal cells pneumatizing the floor of the orbit or the roof of the maxillary sinus. In view of their location, precisely above the region of the maxillary sinus ostium and infundibulum, they can cause narrowing of maxillary sinus ostium or infundibulum, thus predisposing to recurrent maxillary sinusitis.

In our study, inferior turbinate hypertrophy was seen in $74 \%$ cases. Though not a part of osteomeatal complex, it's hypertrophy grossly obstructs the nasal airway and is associated with inflammatory disease in other parts of the nose. Inferior turbinate hypertrophy was reported as 35.9\% (Madani et $\mathrm{al}^{[9]}$ ) This is less than as 
reported by our study. Caughey et $\mathrm{al}^{[18]}$ observed that narrow nasal cavities were associated with maxillary sinus disease.

We found accessory ostia of maxillary sinus in $20 \%$ patients. The bony nasal wall is often deficient behind and below the uncinate process. These defects, the nasal fontanelles, are sites of accessory ostia for the maxillary sinus. Mamatha et $\mathrm{al}^{[3]}$ reported their presence in $22.5 \%$ patients which is correlating with our study.

In our study, CT scan detected mucosal hypertrophy, was seen involving the osteomeatal complex in maximum number of patients i.e. $82 \%$. It is similar to a study by Dua et al ${ }^{[19]}$ at $88 \%$. Fadda et al ${ }^{[5]}$ observed it to be $75.7 \%$.

Maxillary sinus mucosal hypertrophy was also observed in $84 \%$ patients. Bolger et al ${ }^{[20]}$ found in $77.7 \%$, Maru et $\mathrm{al}^{[21]}$ in $70.4 \%$, Dua et $\mathrm{al}^{[19]}$ in $50 \%$, Wani et $\mathrm{al}^{[4]}$ in $70 \%$ and Fadda et $\mathrm{al}^{[5]}$ in $67.1 \%$ cases. This is less than that found in our study.

The comparison of results of present study with some of the other studies in terms of incidence of involvement of various paranasal sinuses on CTscan is shown in table- 3

Table-3Studies Showing Involvement Of Paranasal Sinuses On Ct Scan

\begin{tabular}{|c|c|c|c|c|c|}
\hline Author and year of study & Maxillary sinus & $\begin{array}{c}\text { Anterior } \\
\text { ethmoids }\end{array}$ & $\begin{array}{c}\text { Posterior } \\
\text { ethmoids }\end{array}$ & $\begin{array}{c}\text { Frontal } \\
\text { sinus }\end{array}$ & Sphenoid sinus \\
\hline Bolger et al (1991) & $77.7 \%$ & $84.3 \%$ & $38.6 \%$ & $36.6 \%$ & $25.4 \%$ \\
\hline Maru et al (2001) & $70.4 \%$ & $73.7 \%$ & $52.4 \%$ & $48.3 \%$ & $40.8 \%$ \\
\hline Dua et al(2005) & $50 \%$ & $88 \%$ & $66 \%$ & $32 \%$ & $18 \%$ \\
\hline Wani et al(2009) & $70 \%$ & $87.3 \%$ & $38 \%$ & $15 \%$ & $8.66 \%$ \\
\hline $\begin{array}{c}\text { Fadda et al } \\
(2012)\end{array}$ & $67.1 \%$ & $54.3 \%$ & $10 \%$ & $22.1 \%$ & $10 \%$ \\
\hline Present Study (2015) & $84 \%$ & $74 \%$ & $56 \%$ & $48 \%$ & $20 \%$ \\
\hline
\end{tabular}

Thus, our study is comparable to the studies by Maru et $\mathrm{al}^{[21]}$, Mamatha et $\mathrm{al}^{[3]}$,Fadda et al ${ }^{[5]}$ and Madani et $\mathrm{al}^{[9]}$ in showing that the maxillary sinus is the most common sinus to be involved.Endoscopic findings :- In our study we found agger nasi in $78 \%$, DNS in $76 \%$, ITH in $74 \%$, choncha bullosa in $66 \%$ enlarged ethmoid bulla in $29 \%$, paradoxical middle turbinate in $22 \%$, accessory ostia in $20 \%$.Nasal endoscopy combined with $\mathrm{CT}$ has made the approach to sinonasal disease more specific, rational and accurate.We found a statistical significant correlation between concha bullosa and maxillary sinusitis (right and left choncha bullosa with ipsilateral maxillary sinusitis $\mathrm{p}$ value is. 033 and. 01 , respectively which are $<0.05$ ). Caughey et al ${ }^{[18]}$ observed statistical correlation between concha bullosa and maxillary sinus disease. It could be explained by the fact that choncha bullosa (pneumatised middle turbinate ) can influence negatively on paranasal sinus ventilation and mucociliary clearance in middle meatus. We also found a statistically significant relation between right and left agger nasi cell and ipsilateral frontal sinusitis ( $\mathrm{p}$ value is. 01 and. 0006 which are <.05) and in total $\mathrm{p}$ value is. 029 which is again <.05. Frontal sinus pathology could be because of prominent agger nasi cell can block the frontal recess region. We found a statistical significant relation between paradoxical middle turbinate and ipsilateral maxillary sinusitis ( $\mathrm{p}$ value $<.01$ in both right and left side).In our study another statistical significant correlation was found between DNS and ipsilateral maxillary sinusitis having p value. 04 and. 015 for right and left which are <. 05.

Fadda et $\mathrm{al}^{[5]}$ observed in their study, statistical correlation between concha bullosa and maxillary sinusitis, between medial deviation of uncinate process and anterior ethmoid sinusitis, between agger nasi cells and frontal sinusitis and between septal deviation and maxillary sinusitis. A few studies (Dutra ${ }^{[22]}$, Lusk ${ }^{[23]}$, Milczuk $^{[24]}$ ) have described the anatomical variants prevalence on computed tomography examinations in patients with chronic or recurrent sinusitis. Scribano et $\mathrm{al}^{[25]}$ have observed that the maxillary sinus opacification was significantly more frequent in cases where the concha bullosa determined osteomeatal complex obliteration when compared with cases of concha bullosa without osteomeatal complex obliteration.

Sarna et $\mathrm{al}^{[26]}$ observed that severe septal deviation was a contributing factor for sinusitis. However, some studies (Stallman ${ }^{[27]}$,Scribano ${ }^{[25]}$ )have not demonstrated a causal relationship between nasal septal deviation and sinusitis. The incidence of agger nasi cells has been reported to vary from $3 \%$ to almost $100 \%$ and its presence has been firmly associated with frontal sinusitis (Zinreich et $\mathrm{al}^{[7]}$ ). We found a statistical significant relation between paradoxical middle turbinate and ipsilateral maxillary sinusitis ( $\mathrm{p}$ value <.01 in both right and left side). Azilaet $\mathrm{al}^{[6]}$ concluded that the major consequence of paradoxical middle turbinate variations is narrowing of the middle meatus which can lead to obstruction of infundibular drainage. However the degree of convexity of the middle turbinate is the most important factor to cause the obstruction which will lead to rhinosinusitis. Paradoxical middle turbinate is known to abut against lateral wall and the middle meatus as compared to a normal shaped middle turbinate. It has formed the basis for contact point theory resulting into disturbance with mucocilliary clearance which further leads to development of CRS. In our study most of the paradoxical middle turbinates are more curved inside. So this may be the reason that our results are highly significant. 


\section{Conclusions}

Considering the results obtained, we believe that some anatomical variations of the nose and paranasal sinuses can play an important role in the pathogenesis of chronic rhinosinusitis, and thus may increase the risk of sinusmucosal disease. The significance of anatomical variations is that they impair normal drainage pathway, hinder endoscopic access to distal areas and increase the risk of endoscopic mishaps. Hence, the importance of CT scan and nasal endoscopy is emphasized in patients with persistent symptoms to identify the anatomicalvariations that may contribute to the development of chronic sinus mucosal disease.

\section{Bibliography}

[1]. Bhargawa D. Health related quality of life in patients with rhinosinusitis. In a guide to endoscopic sinus surgery. 2002:47-48

[2]. Ramalingam R and Ramalingam KK. A Hand book on Endoscopic sinus Surgery. ENT Medical Education \& Research Foundation, Chennai, India 1998:4-5.

[3]. Mamatha H, Shamasundar NM, Bharathi MB, Prasanna LC. Variations of ostiomeatal complex and its applied anatomy: a CT study. Indian Journal of Science and Technology. 2010;3(8):904-07.

[4]. Wani AA, Kanotra S, Lateef M, Ahmad R, Qazi SM, Ahmad S. CT scan evaluation of the anatomical variations of the ostiomeatal complex. Indian J Otolaryngol Head Neck Surg. 2009;61:163-68.

[5]. Fadda GL, Rosso S, Aversa S, Petrelli A, Ondolo C, Succo G. Multiparametric statistical correlations between paranasal sinus anatomic variations and chronic rhinosinusitis. Acta Otorhinolaryngol Ital. 2012;32(4):244-51.

[6]. Azila A, Irfan M, Rohaizan Y, Shamim AK.The prevalence of Anatomical Variations in Osteomeatal unit in patients with Chronic Rhinosinusitis. Med J Malaysia 2011;66:3.

[7]. Zinreich S, Kennedy D, Rosenbaum A, et al. Paranasal sinuses: CT imaging requirements for endoscopic surgery. Radiology 1987;163: 769-75

[8]. Sheetal D, Devan PP, Manjunath P, Martin P, Kumar SK, Sreekantha et al. CT PNS - Do we really require before fess? Journal of Clinical and Diagnostic Research 2011;5:179-181.

[9]. Madani SA, Hashemi SA, Javan S, Hoseini AA. Anatomical variants, clinical presentation and pathological findings in patients suffering from chronic rhinosinusitis underwent functional endoscopic sinus surgery. International Journal of Medicine and Medical Sciences. 2014;6(8):190-94.

[10]. Kolvekar VD, Khusru KA, Londhe Pradeep S. Study of Anatomical Variations of Lateral Wall of Nose. UJMDS 2014;02(02):11721.

[11]. El-Shazly AE, Poirrier AL, Cabay J, Lefebvre PP. Anatomical variations of the lateral nasal wall: The secondary and accessory middle turbinates. Clin Anat. 2012;25(3):340-6.

[12]. Leunig A, Betz CS, Sommer B, Sommer F. Anatomical variations of the sinuses: multiplanar CT-analysis in 641 patients Laryngorhinootologie. 2008;87(7):482-89.

[13]. Landsberg R and Friedman M. A computer-assisted anatomical study of the nasofrontal region. Laryngoscope. 2001;111(12):212530 .

[14]. Turgut S, Ercan I, Sayn I, Baak I. The relationship between frontal sinusitis and localization of the frontal sinus outflow tract: A computer-assisted anatomical and clinical study. Arch Otolaryngol Head Neck Surg. 2005;131:518-22.

[15]. Cagici CA, Yilmaz I, Erkan AN, Yilmazer C, Ozluoglu L. Coexistence of the anatomic variations of the paranasal sinuses and thickening of the sinus mucosa. Turkish Archives of Otolaryngology. 2006;44(4):211-17.

[16]. Gupta AK, Gupta B, Gupta N, Tripathi N. Computerized Tomography of Paranasal Sinuses: A Roadmap to Endoscopic Surgery. Clin Rhinol Int J. 2012;5(1):1-10.

[17]. Stoney P, Probst L, Shankar L. CT scanning for functional endoscopic sinus surgery: analysis of 200 cases with reporting scheme. J Otolaryngol. 1993;2272-8.

[18]. Caughey RJ, Jameson MJ, Gross CW, Han JK. Anatomic risk factors for sinus disease: Fact or Fiction? Am J Rhinol. 2005;19(4):334-9.

[19]. Dua K, Chopra H, Khurana AS, Munjal M. CT scan variations in chronic sinusitis. Ind J Radiol Imag. 2005;15(3):315-320.

[20]. Bolger WE, Butzin CA, Parsons DS. Paranasal sinus bony anatomicals and mucosal abnormalities: CT analysis for endoscopic sinus surgery.Laryngoscope 1991;101(1):56-64.

[21]. Maru YK and Gupta V. Anatomic variations of the bone in sinonasal C.T. Indian Journal of Otolaryngology and Head and Neck Surgery. 2001; 53(2):123-28.

[22]. Dutra LD, Marchioni E. Computed tomography evaluation in paranasal sinuses. Radiology Bras 1988; 35 : 161-9.

[23]. Lusk RP, McAlister B, El-Fouley A. Anatomic variation in pediatric chronic sinusitis: A CT study. Otolaryngol Clin North Am 1996; 29(1): $\quad$ 75-91

[24]. Milczuk HA, Dalley RW, Wessbacher FW, Richardson MA. Nasal and paranasal sinus anomalies in children with chronic sinusitis Laryngoscope1993; 103(3): 247-52

[25]. Scribano E, Asenti G, Cascio F, Racchiusa S, Salamone L. Computed tomography in evaluation of anatomic variations of the osteomeatal complex. Radiol Med 1993;86(3):195-9.

[26]. Sarna A, Hayman LA, Laina FJ. Coronal imaging of the osteomeatal unit: anatomy of 24 variants. J Comput Assist Tomogr 2002;26:153-7.

[27]. Stallman JS, Lobo JN, Som PM. The incidence of concha bullosa and its relatioship to nasal septal deviations and paranasal sinusdisease. Am J Neuroradiol 2004;25:1613-8. 